\title{
Sensitive impedimetric biosensor for direct detection of diazinon based on lipases
}

\author{
Nedjla Zehani ${ }^{1,2}$, Sergei V. Dzyadevych ${ }^{3}$, Rochdi Kherrat ${ }^{2}$ and Nicole J. Jaffrezic-Renault ${ }^{1 *}$ \\ 1 UMR 5280, Institut des Sciences Analytiques, Université de Lyon, Villeurbanne, France \\ 2 Laboratory of Environmental Engineering, Faculty of Engineering Sciences, University of Annaba, Annaba, Algeria \\ ${ }^{3}$ Laboratory of Biomolecular Electronics, Institute of Molecular Biology and Genetics, National Academy of Sciences of Ukraine, Kiev, Ukraine
}

\section{Edited by:}

Margarita Stilianova Stoytcheva,

Universidad Autonoma de Baja

California, Mexico

Reviewed by:

Karim Michail, University of Alberta, Canada

Xiliang Luo, Qingdao University of

Science and Technology, China

\section{${ }^{*}$ Correspondence:}

Nicole J. Jaffrezic-Renault, UMR

5280, Institut des Sciences

Analytiques, Université de Lyon, 5

Rue de la Doua, 69100 Villeurbanne,

France

e-mail: nicole.jaffrezic@univ-lyon1.fr
Two novel impedimetric biosensors for highly sensitive and rapid quantitative detection of diazinon in aqueous medium were developed using two types of lipase, from Candida Rugosa (microbial source) (CRL) and from porcine pancreas (animal source) (PPL) immobilized on functionalized gold electrode. Lipase is characterized to specifically catalyze the hydrolysis of ester functions leading to the transformation of diazinon into diethyl phosphorothioic acid (DETP) and 2-isopropyl-4-methyl-6-hydroxypyrimidine (IMHP). The developed biosensors both presented a wide range of linearity up to $50 \mu \mathrm{M}$ with a detection limit of $10 \mathrm{nM}$ for Candida Rugosa biosensor and $0.1 \mu \mathrm{M}$ for porcine pancreas biosensor. A comparative study was carried out between the two biosensors and results showed higher efficiency of Candida Rugosa sensor. Moreover, it presented good accuracy and reproducibility, had very good storage and multiple use stability for 25 days when stored at $4^{\circ} \mathrm{C}$.

Keywords: biosensor, diazinon, lipase, electrochemical impedance spectroscopy

\section{INTRODUCTION}

Chemicals released from agriculture or industry may potentially develop toxic effects in the environment and ecological systems. Among them, pesticides are actively applied and globally used for crop control and to prevent damage to plants, animals, humans, and aliments. Organophosphates constitute the most extensive and manifold group of pesticides, they were developed at the beginning of this century by chemical manipulation of nerve gasses that are so toxic compounds (Osterauer and Kohler, 2008). Their mode of toxicity is the inhibition of acetyl cholinesterase, an enzyme responsible for the hydrolysis of the neurotransmitter acetylcholine (Cabello et al., 2001; Gordon and Mack, 2003; Pesando et al., 2003). This inhibition leads to a continuous stimulation of cholinergic neurons and eventually paralyzes the target organs (Wiener and Hoffman, 2004).

Diazinon after malathion is one of the most commonly used organophosphate pesticides (OPs) in the world, it is extensively used as an insecticide in agriculture to control juvenile forms of insects in soil, plants, fruit, vegetable crops and to control external pet parasites (i.e., mites, leaf miner flies, black cherry aphid, and apple maggot) (Karpouzas and Singh, 2006; UAP. Ca, 2007), it can enters the body via skin contact, feeding, and inhalation (Villeneuve et al., 1972). Furthermore, diazinon is one of the substances most responsible for acute poising via insecticides of humans and wildlife (Keizer et al., 1995). Once applied on crops and other plants, it is easily washed by surface waters and enters the ground water. Eventually, it enters the aquatic environment in large quantities as described in a number of studies and thus may affect a wide range of non-target organisms. The high acute toxicity of diazinon to freshwater fish and aquatic invertebrates is reflected by the $96 \mathrm{~h}$ LC50 of $2 \mathrm{~g} / \mathrm{L}$ in Daphnia magna, of $1.35 \mathrm{mg} / \mathrm{L}$ in O. mykiss, and of $8 \mathrm{mg} / \mathrm{L}$ in Danio rerio (Osterauer and Kohler, 2008). Therefore, the persistence and mobility of diazinon and its metabolites suggest the potential for groundwater contamination, an increasing concentration of diazinon and OPs residues are found to be present in many sampled soils, aquatic eco collected in the United States and Canada and it was the most frequently detected insecticide in surface waters prior to the phase-out of urban uses in 2004 in United States. It degrades in water as a result of hydrolysis, especially under acidic conditions. In sterile water, diazinon was determined to have a half-life of 12 days in acidic water ( $\mathrm{pH} \mathrm{5),}$ 138 days in neutral water ( $\mathrm{pH} 7$ ), and 77 days ( $\mathrm{pH}$ 9). Moreover, because diazinon is fat soluble, there is potential for delayed toxicity if significant amounts of diazinon are stored in fatty tissues and causes diseases with long-term (US NPIC, 2009). Diazinon applied to soils can be also absorbed by plant roots and translocated in plants, soil metabolism studies report soil half-lives for diazinon ranging from 21 to 103 days depending on the type of soil. In addition, oxypyrimidine which is the principal metabolite of diazinon hydrolysis is very mobile in the environment and has been measured up to 72 inches below the surface of soils. Oxypyrimidine appears to be more persistent under at least some conditions compared with diazinon (US NPIC, 2009).

Thus, the need to be understood and evaluate the biological effects of pollutants on aquatic ecosystems has generated (Reddy et al., 2013). In this sense, a large number of studies have used biosensors as functional tools to evaluate the toxicity of such compounds for natural populations (Kumar and D’Souza, 2011). Recently, there has been an intense research effort to develop 
enzymatic biosensor devices for the detection of organophosphorus pesticides. Many enzymes were used for this purpose (Pogacnik and Franco, 1999; Deo et al., 2005; Sajjadi et al., 2009). Among them, we find the lipase which it is an important enzyme in biological systems, where is catalyzes the hydrolysis of ester functions and the transformation of triacylglycerol to glycerol and fatty acids, it is a subclasses of esterases (Bhalchandra et al., 2008).

This paper describes a new biosensor system devoted for environmental application, based on impedimetric transduction incorporating two types of enzymes, lipase from Candida Rugosa CRL (microbial source) and lipase from porcine pancreas PPL (animal source) for the detection of diazinon in aqueous medium. This is the first time that lipase is proposed for the design of diazinon biosensor. This enzyme was used to catalyze the hydrolysis of diazinon (O,O-diethylO-(2-isopropyl-6methyl-4pyrimidyl phosphorothioate) into Diethyl phosphorothioic acid (DETP) and 2-isopropyl-4methyl-6 hydroxypyrimidine (IMHP) (Figure 1). In this work, bioselective membranes were prepared by functionalization of microelectrodes with SAMs and enzyme cross-linking using glutaraldehyde vapor and bovine serum albumin (BSA). As a detection mode, we used electrochemical impedance spectroscopy (EIS) which is one of the electrochemical techniques that have been widely employed to study various chemical and biological phenomena on surfaces and to develop sensors (Yagati et al., 2011). EIS has emerged as a powerful tool to study the biomolecular interactions by detecting changes in capacitance and interfacial electron transfer resistance at the surface electrode occurring during these processes (K'Owino and Sadik, 2005; Ferreira et al., 2010). It is a rapidly developing technique for the label free detection of different types of biosensing events occurring at the surface electrode, example: antigenantibody enzyme-substrate reaction, cell adsorption (Bourigua et al., 2010), it allows such complex recognition events to be probed in a simple, sensitive, label-free, and mediator free strategy (Sadik et al., 2002; Farcas et al., 2010). In this study, the different functionalization steps of gold microelectrodes were first characterized by EIS and cyclic voltammetry (CV), afterward, the analytical characteristics of the developed biosensors were determined. Finally, a comparison study between the two biosensors was carried out.

\section{EXPERIMENTAL}

\section{CHEMICAL AND BIOLOGICAL REAGENTS}

All reagents used in this study were purchased from Sigma Aldrich (Saint Quentin Fallavier) France, including, lipase from Candida

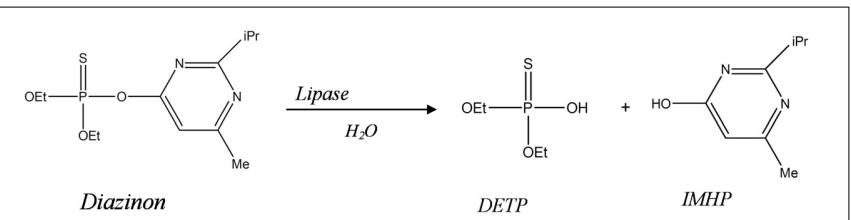

FIGURE 1 | Degradation pathway of diazinon by lipase (Hydrolysis reaction).
Rugosa enzyme (CRL, type VII, $\geq 700$ unit/mg solid), Lipase from porcine pancreas (PPL, type II, 30-90 units/mg protein), bovine serum albumin (BSA), diazinon, parathion methyl, paraoxon methyl, atrazine, sevin, simazine, fenitrothion, sodium phosphate dibasic, sodium phosphate monobasic, $\mathrm{KH}_{2} \mathrm{PO}_{4}, \mathrm{~K}_{2} \mathrm{HPO}_{4}$, glutaraldehyde (grade II, 25\% aqueous solution), glycerol ( $\geq 99 \%$ ), 6-methyl-5propyl-4 pyrimidinone, N-hydroxysuccinimide (NHS), 1-ethyl-3(3-(dimethyl-amino)propyl)carbodiimide (EDC), acidthiol(16mercacaptohexadecanoicacid). Sulfuric acid (96\%), hydrogen peroxide (30\%), ethanol (99\%) was purchased from Fluka. All solutions were made up with ultrapure water (resistivity no less than $18 \mathrm{M} \Omega \mathrm{cm}$ and obtained from a Millipore purification system).

\section{ELECTRODE GOLD PREPARATION AND ENZYME IMMOBILIZATION Gold cleaning}

Before analysis, in order to improve the adhesion of the enzymatic membrane on the electrode surface, gold electrode was firstly immersed in acetone for $10 \mathrm{~min}$ under sonication to remove the resin layer; then, it was immerged for $3 \mathrm{~min}$ in Piranha solution $\left(\mathrm{H}_{2} \mathrm{O}_{2}: \mathrm{H}_{2} \mathrm{SO}_{4}: 3: 7 \mathrm{v} / \mathrm{v}\right)$. Finally the electrode was thoroughly rinsed with ultrapure water and dried under a nitrogen flow.

\section{Functionalization and activation process}

The gold electrode was incubated overnight in $10 \mathrm{mM}$ solution of thiolacid in ethanol, overnight at a temperature of $4^{\circ} \mathrm{C}$, which allowed the formation of a self-assembled monolayer (SAMs) on the surface of the electrode. The thiol functionalized electrode was then rinsed with ethanol in order to remove the unbonded thiol molecules. The resulting monolayer ending with carboxylic acid groups were then activated by an [EDC/NHS] mixture at a concentration of $0.1 \mathrm{~mol} \cdot \mathrm{l}^{-1}$ for $1 \mathrm{~h}$.

\section{Enzyme attachment}

Afterward, the pretreated electrode was rinsed with PBS and dried under nitrogen flow, $10 \mu \mathrm{L}$ of enzyme based solution containing CRL (5\%), BSA (5\%), glycerol (10\%) in phosphate buffer solution $20 \mathrm{mM}, \mathrm{pH}=7.2$ (90\%) was thoroughly homogenized and deposited onto the surface of the working electrode. Then, the sensor was placed in saturated glutaraldehyde vapor (cross-linker) for $30 \mathrm{~min}$, and dried in air at room temperature for $40 \mathrm{~min}$, the biosensor was stored at $4^{\circ} \mathrm{C}$ until further use.

\section{ELECTROCHEMICAL SET-UP: CYCLIC VOLTAMMETRY (CV) AND ELECTROCHEMICAL IMPEDANCE SPECTROSCOPY (EIS)}

Electrochemical measurements were carried out in a conventional one compartment three electrode cell with an internal volume of $5 \mathrm{ml}$ (Verre equipments Collonges au Mont d'or, France), hermetically closed on one side with a planar gold electrode $(300 \mathrm{~nm}$ thickness, deposited on insulated silicon with $0.19 \mathrm{~cm}^{2}$ surface area) used as the working electrode. On the other side, a planar platinum electrode $\left(0.59 \mathrm{~cm}^{2}\right)$ was used as the counter electrode. A saturated calomel electrode from Hach Lange (France) was used as reference electrode. This electrochemical cell was designed to maintain a fixed distance between the electrodes. It was manufactured with two inlets; one for the positioning of the reference 
electrode and the other for OP injections. This feature prevented further manipulation or movements of the electrodes, fixing the geometry of the cell and also ensuring the reproducibility of measurements.

The electrochemical measurements were performed with an electrochemical impedance analyzer "Voltalab PGZ 402" (Hach Lange, France). Data acquisition and processing via "Voltamaster 4" software was provided by Thesame company. CV measurements were performed in $8 \mathrm{mM}$ solution of $\left[\mathrm{Fe}\left(\mathrm{CN}_{6}\right)\right]^{3-/ 4-}$ at scan rate of $100 \mathrm{mV} / \mathrm{s}$. All electrochemical measurements were taken at a frequency range of $100 \mathrm{mHz}-100 \mathrm{kHz}$ at room temperature. Measurements were performed at room temperature in $20 \mathrm{mM}$ PBS buffer solution, $\mathrm{pH}$ 5.2, under magnetic stirring in Faraday cage. A DC potential of $-400 \mathrm{mV}$ was applied; as shown in Figure 2, applying a DC potential of $-400 \mathrm{mV}$ allowed the total impedance of the modified electrode to be minimized before the injection of diazinon. The measured impedance spectra were analyzed in terms of electrical equivalent circuits using the analysis program Zview (Scribner Associates, USA). A classical Randles equivalent circuit presented in Figure 3 was used to fit Nyquist plots, including the two resistive elements $R_{1}$ and $R_{2}$, in which the double layer capacitive was replaced by CPE, a constant phase angle element and Warburg impedance $\mathrm{Zw}$ (cf. Figure 3). $\mathrm{R}_{1}$ corresponds to the Ohmic resistance of the bulk electrolyte and of electrical contacts and $\mathrm{R}_{2}$ to the charge transfer resistance between the solution and the modified electrode surface. $\mathrm{R}_{2}$ is equal to the diameter of semi-circle. Warburg impedance $(\mathrm{Zw})$ is the specific electrochemical element of diffusion and can

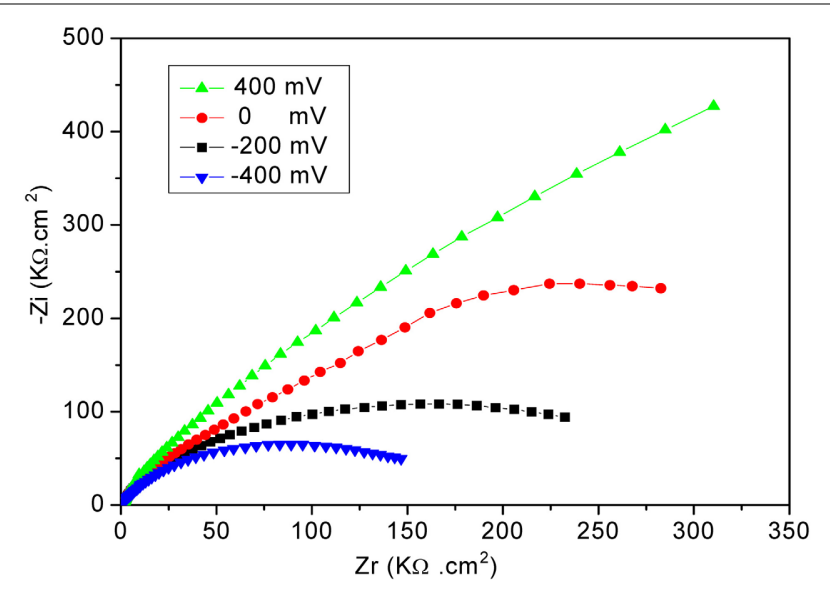

FIGURE 2 | Nyquist plots obtained for the developed biosensor at different applied potentials. Measurements were performed in PBS $20 \mathrm{mM}, \mathrm{pH}$ 5.2, for frequencies ranging from $100 \mathrm{mHz}$ to $100 \mathrm{kHz}$.

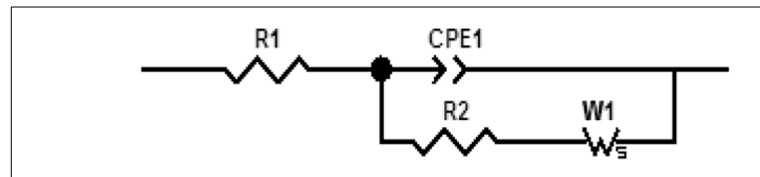

FIGURE 3 | Randles equivalent circuit. be defined as $\left(Z_{w}\right)=(1-j)^{-0.5}$, where, $\sigma$ denotes the Warburg coefficient. CPE takes into account the non-homogeneity of the layer and the impedance of such a non-ideal layer that can be expressed as $Z(\omega)=\mathrm{CPE}^{-1}(j \omega)^{-n}$, where $\omega$ is a circular frequency and $n$ a parameter describing the deviation from an ideal capacitor, varying from 0 to 1 (Katz and Willner, 2003).

\section{RESULTS AND DISCUSSION \\ ELECTROCHEMICAL CHARACTERIZATION OF THE DIFFERENT STEPS OF BIOSENSOR ELABORATION \\ Cyclic voltammetry characterization (CV)}

Figure 4 shows the electrochemical characterization by $\mathrm{CV}$ of the bare and modified electrode in the presence of $8 \mathrm{mM}$ solution of $\left[\mathrm{Fe}(\mathrm{CN})_{6}\right]^{4-/ 3}$. The potential was swept between -0.4 and $0.6 \mathrm{~V}$, at the scan rate of $100 \mathrm{mV} / \mathrm{s}$. As it is clear in the figure, the complete disappearance of the oxidation and reduction peaks after functionalization with the thiol layer confirms the high insulating proprieties of the dense acid thiol layer.

\section{EIS response of the enzymatic biosensor}

In Figure 5, a 2.5 fold increase of $\mathrm{R}_{2}$ was observed by assembling the first layer on the electrode surface, which basically reflects the insulating proprieties of SAMs (Chen et al., 2005). Contrariwise, a decrease of interfacial impedance, correlated to 1.5 fold decrease of $\mathrm{R}_{2}$ was observed following the injection of diazinon, confirming that the hydrolysis of diazinon induces charge redistribution at the functionalized gold electrode/electrolyte interface. The $n$-value was 0.95 for the bare electrode and was reduced to $0.86-$ 0.91 after modification, reflecting only a slight deviation from ideality and a rather capacitive behavior of the corresponding CPE.

\section{ELECTROCHEMICAL DETECTION OF DIAZINON Variation of impedance after diazinon injections}

As can be seen in Figure 6, after increasing concentrations of diazinon contact with CRL biosensor, the total impedance

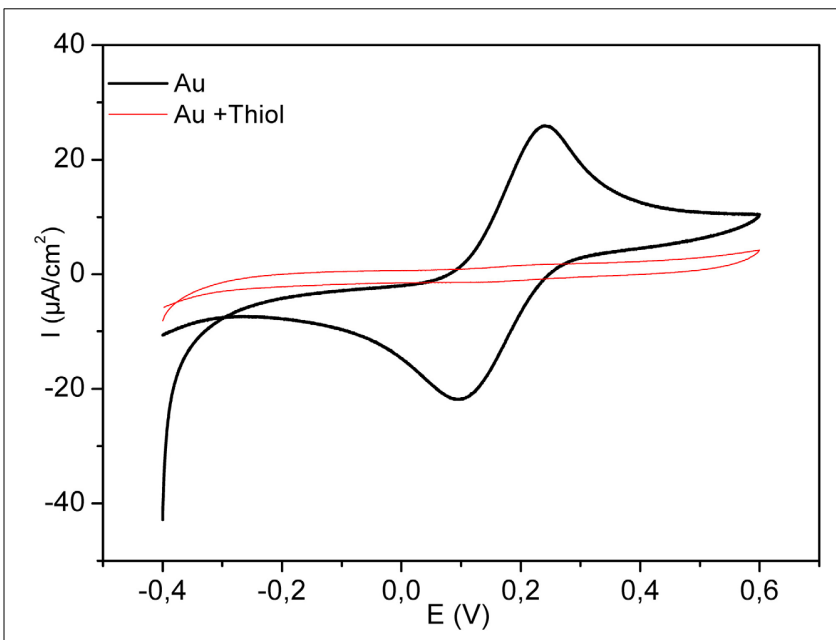

FIGURE 4 | Cyclic Voltammograms for bare electrode (bold plot) and for modified electrode by thiol (thin line). Measurements were performed in $8 \mathrm{mM} \mathrm{Fe}\left(\mathrm{CN}_{6}\right)^{3-/ 4-}$, scan rate $100 \mathrm{mV} / \mathrm{s}$. 
decreases, from 2 to $50 \mu \mathrm{M}$. For concentrations higher than $50 \mu \mathrm{M}$, a saturation effect is observed. The decrease of total impedance is due to a decrease of $\mathrm{R}_{2}$, induced by charge redistribution at the functionalized gold electrode/electrolyte interface due to the enzymatic hydrolysis of diazinon, and an associated increase of interface capacitance.

\section{Calibration curves for CRL and PPL biosensors}

The relationship between biosensor response and diazinon concentration was examined by recording impedance spectra after injection of different concentrations of diazinon in PBS. For both CRL and PPL biosensors, three measurements were performed at each concentration level. To obtain calibration curves, the values of $\Delta R_{2}=R_{2}-R_{2(0)}$ were deduced, where $R_{2(0)}$ refers to $\mathrm{R}_{2}$ for [diazinon] $=0$. Figure 7 presents the calibration plots for both enzymes (a) CRL, (b) PPL, as can be seen, there is a large linear variation of $\Delta R_{2}$ with diazinon concentration up to $50 \mu \mathrm{M}$ for both sensors, with a detection limit of $10 \mathrm{nM}$ for the CRL biosensor and $0.1 \mu \mathrm{M}$ for the PPL based one.

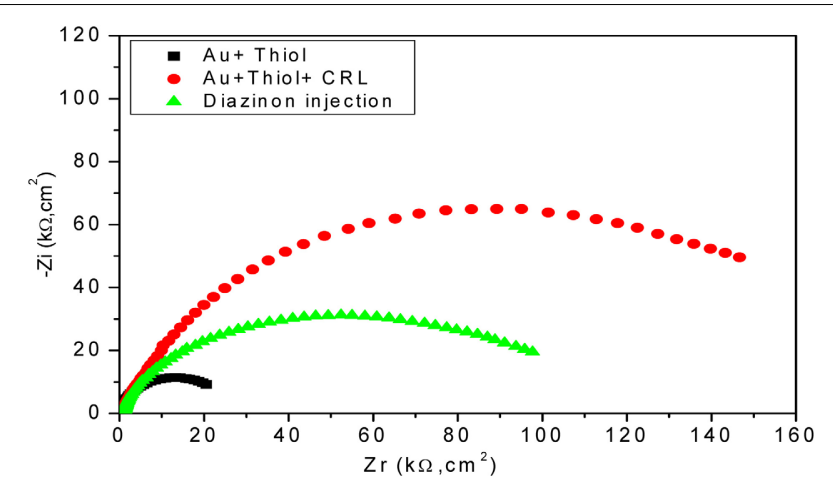

FIGURE 5 | Nyquist diagrams for different layers of developed biosensor with CRL. Measurements were carried out in PBS $20 \mathrm{mM}$, pH 5.2 with a frequency range of $100 \mathrm{mHz}-100 \mathrm{kHz}$.

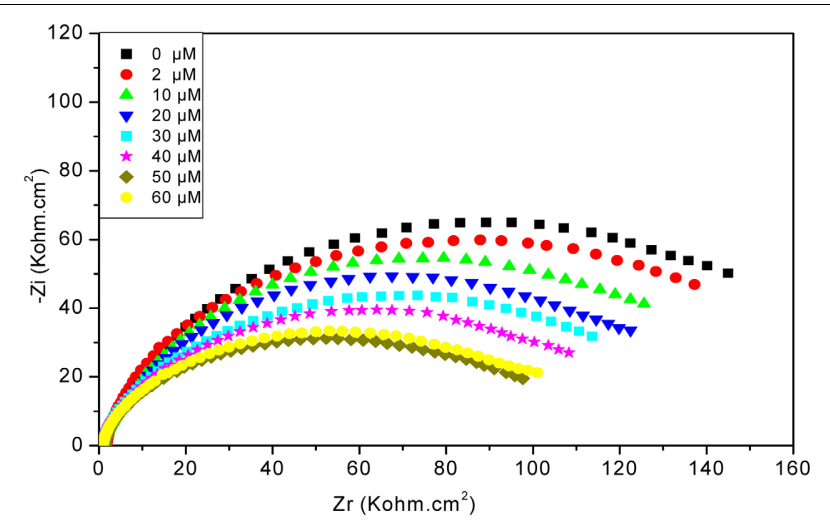

FIGURE 6 | Nyquist diagrams obtained with CRL biosensor, after injection of different concentrations of diazinon. Measurements were carried out in PBS $20 \mathrm{mM}$, pH 5.2 with a frequency range of $100 \mathrm{mHz}-100 \mathrm{kHz}$
Besides, the relative variation of $\mathrm{R}_{2}$ obtained with enzyme CRL is larger (factor 2.5) than that obtained with PPL and as it is shown in Table 1 that the correlation coefficient and sensitivity of CRL biosensor $\left(S=0.78 \mathrm{k} \Omega \mathrm{cm}^{2}\right)$ are better than those obtained by PPL sensor $\left(S=0.49 \mathrm{k} \Omega \mathrm{cm}^{2}\right)$. Therefore, the analytical performances of CRL based biosensor are the best. This CRL based biosensor had a detection limit of $10 \mathrm{nM}$ which is however higher than that biosensors based on inhibition of AchE (Yi et al., 2013), but it presented a large linear range and it was better than enzymatic biosensors already reported like a potentiometric $\mathrm{OPH}$ based biosensor (Mulchandani et al., 1999, 2001), an amperometric tyrosinase based biosensor (Tanimoto de Albuquerque and Ferreira, 2007), a tyrosinase based oxygen biosensor (Russell Everett and Rechnitz, 1998), (cf. Table 2). Furthermore, this value is sufficient to allow diazinon determination in industrial waste waters and make

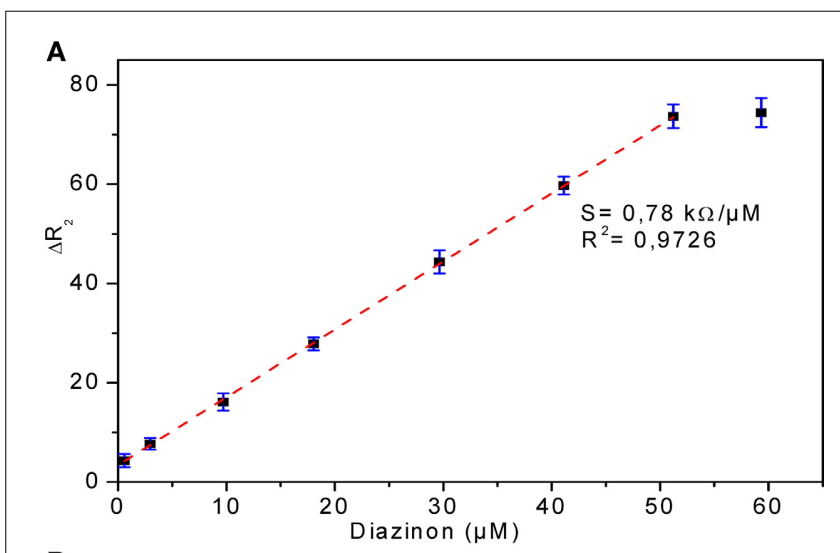

B

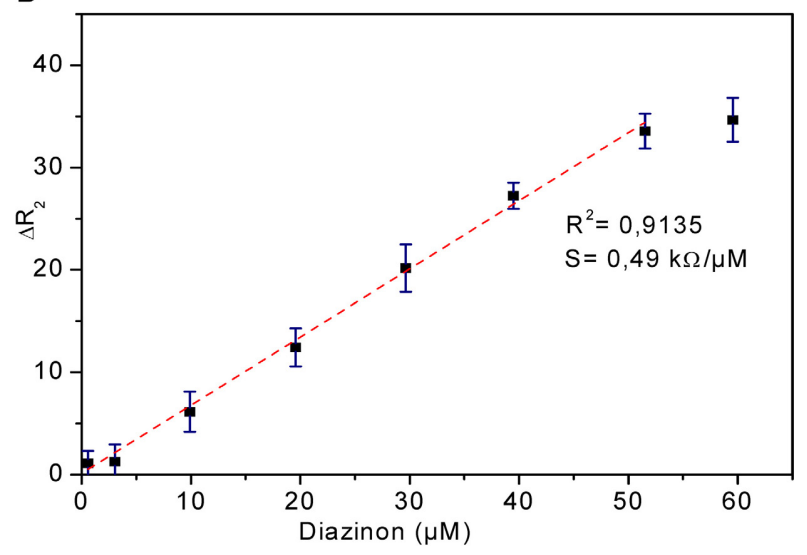

FIGURE 7 | Calibration curves of diazinon enzymatic biosensors (A) CRL, (B) PPL. Operational conditions: $20 \mathrm{mM}$ phosphate buffer, pH 5.2 at room temperature. Each point is the mean of three values.

Table 1 | Analytical characteristics of enzymatic biosensors.

\begin{tabular}{lccc}
\hline Enzyme & Sensitivity & Linear range $(\boldsymbol{\mu} \mathbf{M})$ & Detection limit $(\boldsymbol{\mu} \mathbf{M})$ \\
\hline $\mathrm{CRL}$ & $0.78 \mathrm{k} \Omega / \mu \mathrm{M}$ & Up to 50 & 0.01 \\
$\mathrm{PPL}$ & $0.49 \mathrm{k} \Omega / \mu \mathrm{M}$ & Up to 50 & 0.1
\end{tabular}


Table 2 | Analytical characteristics of enzymatic biosensors for the detection of diazinon.

\begin{tabular}{|c|c|c|c|c|c|}
\hline Target analyte & Transduction & Linear range & LOD ( $\mu \mathrm{M})$ & Enzyme & References \\
\hline Diazinon & Amperometric & $5-50 \mu \mathrm{M}$ & 5 & Tyrosinase & Russell Everett and Rechnitz, 1998 \\
\hline Diazinon & Potentiometric & $0.13-2.8 \mathrm{mM}$ & 5 & $\mathrm{OPH}$ & Mulchandani et al., 1999 \\
\hline Diazinon & Amperometric & $0.06-016 \mu \mathrm{M}$ & 0.06 & Tyrosinase & $\begin{array}{l}\text { Tanimoto de Albuquerque and } \\
\text { Ferreira, } 2007\end{array}$ \\
\hline Diazinon & Amperometric & $0.46-8.56 \mathrm{mM}$ & 2 & $\mathrm{OPH}$ & Mulchandani et al., 1998 \\
\hline Diazinon & SiQDs fluorescence & / & $2.22 \times 10^{-4}$ & AchE and $\mathrm{ChOx}$ & Yi et al., 2013 \\
\hline Diazinon & Photothermal & / & 32.86 & AchE & Pogacnik and Franco, 1999 \\
\hline Diazinon & Impedimetric & $0.01-50 \mu \mathrm{M}$ & 0.01 & $\mathrm{CRL}$ & This work \\
\hline Diazinon & Impedimetric & $0.1-50 \mu \mathrm{M}$ & 0.1 & PPL & This work \\
\hline
\end{tabular}

LOD, limit of detection.

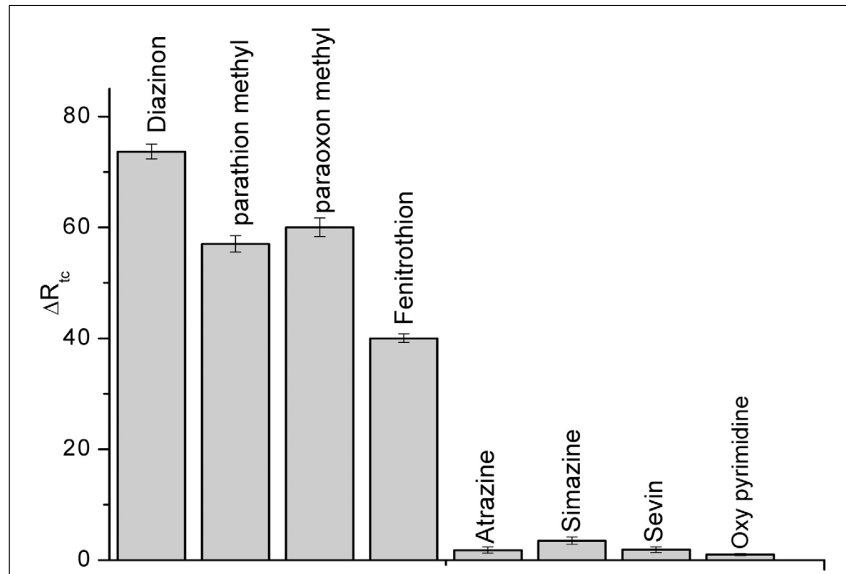

FIGURE 8 | Interference study using CRL impedimetric biosensor. Experiments were performed in 20 mM PBS solution, pH 5.2 at room temperature. Each point is the mean of three values. the biosensor suitable for on-line environmental monitoring applications.

The enzymatic biosensor was also evaluated for matrix effect of natural compounds in real samples. Diazinon was spiked in water from La Chaudanne river-Lyon ( $\mathrm{pH}$ of samples water was adjusted from original 7.5 to 5.2 and analyzed within $24 \mathrm{~h}$ after collection). the responses of the biosensor in the river water were almost similar to that in the buffer, validating the potential utility of the present biosensor for detection of OPs contaminated natural waters.

\section{Selectivity of biosensor}

Selectivity is a fundamental component of biosensor, therefore, it was tested for the detection of some compounds: parathion methyl, paraoxon methyl, fenitrothion, (organophosphate pesticides), atrazine, sevin, simazine (carbamates) and also for oxypyrimidine; the metabolite of diazinon at the concentration of $50 \mu \mathrm{M}$, the results are presented in Figure 8. Such as it is clear in the figure, this CRL biosensor is not specific for individual pesticide but to a class of organophosphate pesticides. Conversely, the carbamates and oxypyrimidine did not interfere.

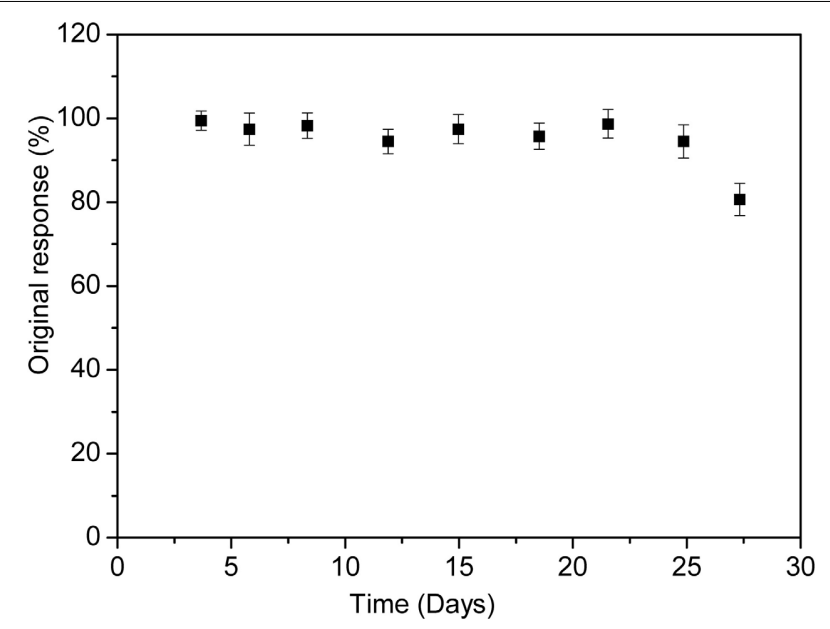

FIGURE 9 | Stability of enzymatic biosensor, response to $50 \mu \mathrm{M}$ diazinon in phosphate buffer, pH 5.2.

\section{Stability and reproducibility of CRL biosensor}

Reproducibility and stability are among the key factors of a sensor's performance, the reproducibility of the enzymatic biosensor was tested for three different sensors in the concentration range from 10 to $50 \mu \mathrm{M}$. The variation coefficient obtained from three measurements was very good; it was between 2 and $5 \%$ in the concentration range studied.

To investigate the long-term storage stability and multiple use capability, the enzymatic biosensor was used for 1 month to measure the response to $50 \mu \mathrm{M}$ of diazinon. During that time, the biosensor was stored at $4^{\circ} \mathrm{C}$ in $20 \mathrm{mM}$ phosphate buffer ( $\mathrm{pH} 7.2)$. As demonstrated in Figure 9, the biosensor was stable for 25 days, after this, only $20 \%$ of the initial response was lost. Therefore, life time of this biosensor can be estimated to be one month. This storage time was as stable as other previously reports of organophosphate pesticides detection (32 and 30 days) (Mulchandani et al., 2001; Kumar et al., 2006). However, it exceeds those earlier reported in the literature as amperometric screen printed tyrosinase-modified electrodes (10 days) and microbial Sphingomonas sp biosensor for methyl parathion detection (18 days) (Kumar et al., 2006; Tanimoto de Albuquerque and Ferreira, 2007). 


\section{CONCLUSION}

In this work, two impedimetric biosensors were developed for the detection of diazinon. Two different types of lipase were immobilized on the surface of functionalized gold electrode. Both biosensors presented a wide linear range and low detection limits, but the performance of CRL based biosensor is better than PPL biosensor (sensitivity and detection limit). This novel CRL biosensor for direct determination of diazinon is simple, one step with rapid response and large dynamic range. Moreover, it is low cost and does not require any expensive measurement apparatus. Unlike the other biosensors based on OPH or AchE, it is specific only for organophosphate pesticides which make it very promising analytical tool for the detection of organophosphate pesticides in real samples. Thus, it will be ideal for on line monitoring of detoxification processes for the treatment of wastewaters generated by the industrial production of organophosphate-pesticides.

\section{ACKNOWLEDGMENT}

The authors thank EC for financial support through Marie Curie NANODEV grant $\mathrm{N}^{\circ} 318524$.

\section{REFERENCES}

Bhalchandra, K. V., Ganesh, C. I., Ponrathnam, S., Kulkarni, B. D., and Sanjay, N. N. (2008). Immobilization of Candida Rugosa lipase on poly (allyl glycidyl etherco-ethylene glycol dimethacrylate) macroporous polymer particles. Bioresour. Technol. 99, 3623-3629. doi: 10.1016/j.biortech.2007.07.035

Bourigua, S., Hnaien, M., Besseuille, F., Lagarde, F., Dzaydevych, S., Maaref, A., et al. (2010). Impedimetric immunosensor based on SWCNT-COOH modified gold microelectrodes for label-free detection of deep venous thrombosis biomarker. Biosens. Bioelectron. 26, 1278-1282. doi: 10.1016/j.bios.2010. 07.004

Cabello, G., Valenzuela, M., Vilaxa, M., Duran, A., Rudolph, V., Herpic, I., et al. (2001). A rat mammary tumor model induced by the organophosphorus pesticides parathion and malathion, possibly through acetylcholine inhibition. Environ. Health Perspect. 109, 471-479. doi: 10.1289/ehp. 01109471

Chen, H., Heng, C. K., Puiu, P. D., Zhou, X. D., Lee, A. C., Lim, T., et al. (2005). Detection of Saccharomyces cerevisiae immobilized on self-assembled monolayer (SAM) of alkanethiolate using electrochemical impedance spectroscopy. Anal. Chem. Acta 554, 52-59. doi: 10.1016/j.aca.2005. 08.086

Deo, R. P., Wang, J., Block, I., Mulchandani, A., Joshi, K. A., Trojanowicz, M., et al. (2005). Determination of organophosphate pesticides at a carbon nanotube/organophosphorus hydrolase electrochemical biosensor. Anal. Chim. Acta 530, 185-189. doi: 10.1016/j.aca.2004.09.072

Farcas, M., Cosman, N., Tings, D., Rscoe, S., and Omanovic, S. (2010). A comparative study of electrochemical techniques in investigating the adsorption behavior fibrinogen on platinum. J. Electroanal. Chem. 649, 206-218. doi: 10.1016/j.jelechem.2010.04.004

Ferreira, D. C., Mendes, R., Kubota, L., and Braz, J. (2010). Kinetic studies of HRP adsorption on ds-DNA immobilized on gold electrode surface by EIS and SPR. Chem. Soc. 21, 1648-1655. doi: 10.1590/S010350532012

Gordon, C. G., and Mack, C. (2003). Influence of gender on thermoregulation and cholinesterase inhibition in the long-evans rat exposed to diazinon. J. Toxicol. Environ. Health 66, 291-304. doi: 10.1080/15287390306371

Karpouzas, D. G., and Singh, K. B. (2006). Microbial degradation of organophosphorus xenobiotics: metabolic pathways and molecular basis. Adv. Microb. Physiol. 51, 185-225. doi: 10.1016/S0065-2911(06)51003-3

Katz, E., and Willner, I. (2003). Probing biomolecular interactions at conductive and semiconductive surfaces by impedance spectroscopy: routes to impedimetric immunosensors, DNA-sensors and enzyme biosensors. Electroanalysis 15, 913-290. doi: 10.1002/elan.200390114

Keizer, J., D’Agostino, G., Nagel, R., Volpe, T., Gnemi, P., and Vittozzi, L. (1995). Enzymological differences of AChE and diazinon hepatic metabolism: correlation of in vitro data with the selective toxicity of diazinon to fish species. Sci. Total Environ. 171, 213-220. doi: 10.1016/0048-9697(95) 04687-0

K'Owino, I., and Sadik, O. (2005). Impedance spectroscopy: a powerful tool for rapid biomolecular screening and cell culture monitoring. Electroanalysis 17, 2101-2113. doi: 10.1002/elan.200503371

Kumar, J., and D'Souza, S. F. (2011). Microbial biosensor for detection of methyl parathion using screen printed carbon electrode and cyclic voltammetry. Biosens. Bioelectron. 25, 4289-4293. doi: 10.1016//j.bios.2011. 04.027

Kumar, J., Jha, S. K., and D'Souza, S. F. (2006). Optical microbial biosensor for the detection of methyl parathion pesticide using Flavobacterium sp whole cells adsorbed on glass fiber filters as disposable biocomponent. Biosens. Bioelectron. 21, 2100-2105. doi: 10.1016/j.bios.2005.10.012

Mulchandani, A., Chen, W., Mulchandani, P., Wang, J., and Rogers, K. M. (2001). Biosensor for direct determination of organophosphate pesticides. Biosens. Bioelectron. 16, 225-230. doi: 10.1016/S0956-5663(01) 00126-9

Mulchandani, A., Kaneva, I., and Chen, W. (1998). Biosensor for direct determination of organophosphate nerve agents using recombinant Escherichia coli with surface-expressed organophosphorus hydrolase. 2. Fiber-optic microbial biosensor. Anal. Chem. 70, 4140-4145. doi: 10.1021/ac9806431

Mulchandani, P., Mulchandani, A., Kaniva, I., and Chan, W. (1999). Biosensor for direct determination of organophosphate nerve agents. 1. Potentiometric enzyme electrode. Biosens. Bioelectron. 14, 77-85. doi: 10.1016/S09565663(98)00096-7

Osterauer, R., and Kohler, H. (2008). Temperature- dependent effects of the pesticides thiacloprid and diazinon on the embryonic development of zebrafish (Danio rerio). Aquat. Toxicol. 86, 485-494. doi: 10.1016/j.aquatox.2007. 12.2013

Pesando, D., Huitorel, P., Dolcini, V., Angelini, C., Guidetti, P., and Falugi, C. (2003). Biological targets of neurotoxic pesticides analysed by alteration of developmental events in the Mediterranean sea urchin, Paracentrotus lividus. Mar. Environ. Res. 55, 39-57. doi: 10.1016/S0141-1136(02)00215-5

Pogacnik, L., and Franco, M. (1999). Determination of organophosphate and cabamate pesticides in spiked samples of tap water and fruit juices by a biosensor with photothermal detection. Biosens. Bioelectron. 14, 569-578. doi: 10.1016/S0956-5663(99)00029-9

Reddy, K. G., Madhavi, G., Swamy, B., Reddy, S., Reddy, A. V., and Medhavi, V. (2013). Electrochemical investigations of lipase enzyme activity inhibition by methyl parathion pesticide: voltammetric studies. J. Mol. Liq. 180, 26-30. doi: 10.1016/j.molliq.2012.12.032

Russell Everett, W., and Rechnitz, G. A. (1998). Mediated bioelectrocatalytic determination of organophosphorus pesticides with a tyrosinase- based oxygen biosensor. Anal. Chem. 70, 807-810. doi: 10.1021/ac9709581

Sadik, O. A., Xu, H., Gheorghiu, E., Andreescu, D., Balut, C., Gheorghui, M., et al. (2002). Differential impedance spectroscopy for monitoring protein immobilization and antibody-antigen reactions. Anal. Chem. 74, 3142-3150. doi: $10.1021 / \mathrm{ac} 0156722$

Sajjadi, S., Ghourchian, H., and Tavakoli, H. (2009). Choline oxidase as a selective recognition element for determination of paraoxon. Biosens. Bioelectron. 24, 2509-2514. doi: 10.1016/j.bios.2009.01.008

Tanimoto de Albuquerque, D., and Ferreira, L. F. (2007). Amperometric biosensing of carbamate and organophosphate pesticides utilizing screen printed tyrosinase modified electrodes. Anal. Chem. Acta 596, 210-221. doi: 10.1016/jaca.2007.06.013

UAP. Ca (United Agri Products Canada INC). (2007). Diazinon Technical Fact Sheet. http://www.uap.ca/francais/products/documents/Diazinon50WF_ datapak12_FEB_2007_000.pdf

US NPIC (National Pesticide Information Center, Oregon State University Extension Services). (2009). Diazinon Technical Fact Sheet. Available online at: http://npic.orst.edu/factsheets/diazinontech.pdf (Accessed October 12, 2012).

Villeneuve, D. C., Willes, R. F., Lacroix, J. B., and Phillips, W. E. J. (1972). Placental transfer of ${ }^{14} \mathrm{C}$-parathion administered intravenously to sheep. Toxicol. Appl. Pharmacol. 21, 201-205. doi: 10.1016/0041-008X(72)90010-5

Wiener, S. W., and Hoffman, R. (2004). Nerve agents: a comprehensive review. J. Intensive Care Med. 19, 22-37. doi: 10.1177/0885066603258659

Yagati, A. K., Lee, T., Min, J., and Choi, J. W. (2011). Amperometric sensor for hydrogen peroxide based on direct electron transfer of 
spinach ferredoxin on Au electrode. Bioeletrochemistry 80, 169-174. doi: 10.1016/j.bioelechem.2010.08.002

Yi, Y., Zhu, G., Liu, C., Hang, Y., Zhang, Y., Li, H., et al. (2013). A label-free silicon quantum dots- based photoluminescence sensor for ultrasensitive detection of pesticides. Anal. Chem. 85, 11464-11470. doi: 10.1021/ac403257p

Conflict of Interest Statement: The authors declare that the research was conducted in the absence of any commercial or financial relationships that could be construed as a potential conflict of interest.

Received: 24 April 2014; accepted: 13 June 2014; published online: 04 July 2014.
Citation: Zehani N, Dzyadevych SV, Kherrat $R$ and Jaffrezic-Renault NJ (2014) Sensitive impedimetric biosensor for direct detection of diazinon based on lipases. Front. Chem. 2:44. doi: 10.3389/fchem.2014.00044

This article was submitted to Analytical Chemistry, a section of the journal Frontiers in Chemistry.

Copyright (c) 2014 Zehani, Dzyadevych, Kherrat and Jaffrezic-Renault. This is an open-access article distributed under the terms of the Creative Commons Attribution License (CC BY). The use, distribution or reproduction in other forums is permitted, provided the original author(s) or licensor are credited and that the original publication in this journal is cited, in accordance with accepted academic practice. No use, distribution or reproduction is permitted which does not comply with these terms. 